\title{
Le dialogue éternel
}

\section{U I}

ON amour lumineux, Amante, t'auréole, Et, fastueusement, de par ma volonté, $\mathrm{Je}$ te vois, Bien-Aimée, ô ma petite idole,

Parée comme une Icône et lasse de beauté.

Le somptueux collier est lourd á ton cou frèle. Les bracelets, pesants á tes poignets menus, Et tes bagues, ou l'or aux pierreries $s^{\prime}$ emmèle, Font paraître tes doigts plus longs et plus ténus.

Et je tremble, ô ma claire Princesse futile, Que mon viril amour, si fort et si hautain, $\mathrm{Ne}$ soit plus écrasant á ton âme fragile Que ces bijoux massifs á ton corps enfantin.

\section{E L L E}

Que importe, Aimé? Je viens, come un enfant bien sage, Puisque tu l'as voulu, m'asseoir en ta maison, Et, dans le cercle étroit qu'éclaire ton visage, Concentrer ma ferveur des lointains horizons.

Au lieu de la saveur amère des voyages, Mes poumons s'enfleront au vent de ton amour, 
Et mon regard, curieux de changeantes images, Boira dans ton regard tout l'infini des jours.

O Maitre Bien Aimé... Ma petite âme en cage Sera, sous tes doigts surs, l' armonieux roseau Qui chante, dans l'odeur humide des herbages, Les rêves infinis du pâtre et du troupeau.

Je serai, mon ami, forte de ton courage;

Tu seras exalté de mon naif orgueil.

Et nous deviendrons vieux, nous serrant davantage

Pour tenir tous les deux dans le mème cercueil.

\section{V RES SE}

(Cache lui ton ennui parce qu'elle est une femme.

Francis Jammes).

Non non... donne-le-moi, ton chagrin rauque, énorme,

Et je le bercerai dans mon coeur apaisant

Jusqu'a ce qu'il s'endorme.

J'aurais voulu, chair de ma chair, sang de mon sang.

Plus que mon Bien-Aimé que tu sois mon enfant.

Voir s'épanouir en toi mon rêve éblouissant

De suprème tendresse.

Te laire grand, génial, plus qu'un Roi, comme un Dieu.

$\mathrm{Te}$ faire beau. Te faire bon. Te faire heureux.

Et puis, t'ayant doté avec trop de largesse,

Ayant, dans ta vigueur, mis trop de ma jeunesse,

Trop de ma clarté dans tes yeux,

Mourir de t'avoir engendré... De cette ivresse... 